\title{
Los rituales de la descomposición del cuerpo en Cuentos fríos de Virgilio Piñera
}

\section{The Rituals of the Decomposition \\ of the Body in Cuentos fríos by Virgilio Pinera}

\section{Luis Charry*}

University of Maryland, Estados Unidos

DOI: http://dx.doi.org/cl.23.2016.9

* Doctor en Literatura Latinoamericana. The George Washington University y University of Maryland. Correo electrónico: lcharry@umd.edu 


\section{Resumen}

El cuerpo es una de las grandes obsesiones de Virgilio Piñera y esta obsesión se manifiesta de un modo insistente en toda su obra. En este ensayo analizaré las distintas instancias en que el cuerpo $-\mathrm{y}$, su materia prima, la carne- irrumpe en Cuentos fríos y cómo dichas irrupciones operan en el marco de una poética en la que, de acuerdo con Antón Arrufat, el alma no va hacia el cuerpo sino más bien el cuerpo se desplaza hacia una cierta "alma hipotética". Por medio de este desplazamiento se establece entonces un conflicto productivo entre el yo y el cuerpo: un cuerpo siempre en estado de alerta, al borde de la descomposición.

\section{Palabras clave}

Piñera, Lezama Lima, Yo, Cuerpo, Cuento.

\section{Abstract}

The body is one of the great obsessions of Virgilio Piñera and this obsession manifests itself in an insistent way throughout his works. In this essay I will discuss the various instances in which the body -and its raw material, the fleshbreaks into Cuentos fríos and how these irruptions operate within the framework of a literary style in which, according to Antón Arrufat, the soul does not go to the body but rather the body moves towards a certain "hypothetical soul." A productive conflict between the self and the body is then established through this displacement: a body always on alert, on the verge of breakdown.

\section{Keywords}

Piñera, Lezama Lima, Self, Body, Short story. 
Aunque parezca un oxímoron o una refinada licencia poética, lo cierto es que una de las grandes fantasías eróticas de Virgilio Piñera fue la disolución matrimonial del yo y el cuerpo, cuyo clímax nupcial no se encuentra localizado en un momento específico de su obra sino en diversos momentos: La carne de René, "Discurso a mi cuerpo", Cuentos frios, por mencionar apenas los ejemplos más visibles, los puntos culminantes donde la disolución (o mejor: la anulación) casi se consoli$\mathrm{da}^{1}$. Esta disolución se convertiría al mismo tiempo en una obsesión, una obsesión altamente productiva en materia literaria ya que Piñera intentó combatirla desde dos frentes de guerra en apariencia antagónicos: la poesía y la prosa. Por su pertinencia para este ensayo quisiera referirme inicialmente a "Discurso a mi cuerpo" antes de pasar a analizar con mayor profundidad ciertos aspectos del yo y el cuerpo en Cuentos fríos. Paralelamente, abordaré la ardiente descomposición de la carne, ya que sin duda es el motivo complementario (la "materia prima" del litigio en cuestión) del universo literario de Piñera. Así, pues, las preguntas iniciales realmente serían: ¿cómo se estructura el conflicto entre el yo y el cuerpo en Cuentos fríos de Virgilio Piñera y cuáles son los antecedentes fundamentales de este conflicto?

\section{Yo acuso: escenas inaugurales de un juicio contra el cuerpo}

¿Qué es "Discurso a mi cuerpo"? ¿Qué hay ahí?¿Qué es, pues, "Discurso a mi cuerpo"? ¿Qué hay ahí? En principio se trata de un elegante prontuario estilístico donde el "yo" de Piñera levanta una serie de cargos en contra del "cuerpo" de Piñera. El yo acusa y el cuerpo recibe las acusaciones con la misma imperturba-

1 En este sentido las palabras de Antón Arrufat (1994) son esclarecedoras: "Es claro que Piñera no estaba de acuerdo con su cuerpo. Más tarde llamará a este desacuerdo un real 'divorcio'. Divorcio que no implica por supuesto matrimonio previo. Esto es indudable: Piñera se consideraba un hombre feo, de boca sin atractivo, flaco, de mentón hundido y frente prominente, y había comenzado a perder el cabello, lo que consideraba hermoso eran sus ojos y sus manos, de los que hacía gala. Si para cualquiera considerarse feo, tener una relación desacordada con su cuerpo, constituye una desdicha, lo es más para un homosexual. El homosexual tiene el mito de la belleza, y vive en perenne conquista del cuerpo. En el comercio sexual del mundo, en el erotismo, el cuerpo de Piñera se hallaba en desventaja" (p.26). Esta exclusión generada por las "falencias del cuerpo" tuvo un correlato histórico (e histérico) en el mismo "corpus literario" de la obra de Piñera, tal como lo ilustra por ejemplo aquella anécdota de exclusión encarnada en el Che Guevara y reproducida hasta la saciedad en múltiples artículos académicos y periodísticos; cito la versión de José Quiroga (1995): “According to the Spanish writer Juan Goytisolo, and as recounted by Guillermo Cabrera Infante, when Ernesto "Che" Guevara saw a volume of Virgilio Piñera's Teatro completo in the Cuban embassy, he hurled it against a wall: 'How dare you have in our embassy a book by this foul faggot!', he shouted, to an astonished and at that time, fairly closeted, Goytisolo" (p.168). La anécdota anula de paso, como bien sostiene Quiroga (1999) en otro ensayo, cualquier lectura de la obra de Piñera enclaustrada exclusivamente en los confines de la homosexualidad: "At this point in time, when the competition over Piñera's body and legacy is part of a general 'coming to terms' with the history of homosexualities and revolution, it is important to be aware of the gains and losses of visibility as it colludes with the designs of a state that can be repressive at one point, and proclaim liberation and 'rectification' at another" (p.121). 
bilidad de siempre, la misma de todos los combates anteriores. Mudo e impávido, el cuerpo acepta los golpes bajos del yo, los acepta sin remordimiento, con culposa aceptación, como si las siguientes palabras de Foucault (2008) adquirirían de golpe un sentido revelador: "El cuerpo: superficie de inscripción de los acontecimientos (mientras que el lenguaje los marca y las ideas los disuelven), lugar de disociación del Yo (al que trata de prestar la quimera de una unidad substancial); volumen en perpetuo desmoronamiento" (p.32). Indudablemente, en los primeros versos de "Discurso a mi cuerpo" el yo pasa a la carga y asume el papel de un yo acusatorio y triunfador; a lo mejor por eso se desliza entre líneas una convicción hasta cierto punto eufórica: "Como en el suceso criminal te digo ahora, mi cuerpo: 'Al fin te tengo'. Tú sabes de estas largas persecuciones; en verdad el discurso de mis años ha resultado ser una persecución estremecida de ti, de ti, cuerpo que escapas siempre a este momento supremo" (Piñera, 1990, p.35).

El conflicto yo-cuerpo/cuerpo-yo entonces se convierte (para seguir con la jerga policial) en el trasfondo de un arresto, o, si se quiere, en la culminación de un asedio, de un asedio no fechado, donde hay un leve aire de seducción: el yo va tras el cuerpo (de ahí que "celebre" su triunfo) como si se tratara de un arrollador cortejo erótico. Sin embargo, el conflicto yo-cuerpo/cuerpo-yo (conflicto judicial, conflicto erótico: es lo de menos) no se cristaliza a estas alturas en el modo en que el yo ha atrapado al cuerpo -“Al fin te tengo", después de todo, no es más que un pretexto poético-, sino más bien en el modo en que lo acusa, es decir: en los cargos que le formula. Evidentemente, es necesario conocer estos detalles antes de que el juez dicte la sentencia, sobre todo porque el juez " $y$ " el jurado son el mismo Virgilio Piñera ${ }^{2}$.

Que el yo enumere una serie de cargos -al cuerpo se lo acusa de ser responsable de yantar, de yacer, de gástricas o pulmonares calenturas, de los baños casi obligatorios, de las fiebres, de rendirle pleitesía a médicos y cirujanos, de cagar-no garantiza que la verdad haya salido a flote. De ahí que deba volver aquí a retomar la pregunta arriba planteada: ¿de qué acusa "realmente" el yo de Piñera al cuerpo

2 Si Piñera no fuera partidario de la hostilidad entre los binomios - el "yo" y el "cuerpo", el "mar" y la "isla"- no descartaríamos que él mismo fuera (en persona, diría) parte sustancial de la audiencia. En cualquier caso, el fallo será condenatorio (sea cual sea la elección): tanto el "yo" como el "cuerpo" no tienen escapatoria, ni pueden librarse el uno del otro, y por eso deberán pagar una pena ad infinitum en prisión. El yo prisionero en la cárcel del cuerpo, y viceversa. En otro plano artístico, en otro lamento alucinatorio de emancipación, Piñera (2000) proclama: "La maldita circunstancia del agua por todas partes / me obliga a sentarme en la mesa del café. / Si no pensara que el agua me rodea como un cáncer / hubiera podido dormir a pierna suelta” (p.37). ¿Es el mar la cárcel de la isla? ¿Es un cuerpo el carcelero de otro cuerpo? ¿No es esto también un típico caso de prisión perpetua? 
de Piñera? Es una pregunta tal vez un poco intimidatoria, tal vez un poco irritante, pero la respuesta borra ciertas zonas de incertidumbre: en Piñera el cuerpo ha sido siempre un espacio castrador, un espacio inadecuado para el "yo", un "yo" con cierto temple de rebeldía, de rebeldía creadora, que no puede ir más allá de las fronteras claramente delimitadas por cada parte del cuerpo. Eso Piñera no se lo perdona. Y por eso lo acusa. Aunque al final no pueda condenarlo: "Hablaba de artilugio y artilugio fue cuando te anunciaba que al fin te tenía... Pero la verdad es que ni te tengo ni te has escapado; estás en tu estado midiendo tu soledad por la mía; tu sordera por mi alarido; tu desconocimiento por el mío" (Piñera, 1990, p.36). Con estas palabras se levanta la sesión. Aunque esto no quiere decir que las implicaciones judiciales o eróticas de inmediato se desvanezcan.

Desde otra perspectiva, "Discurso a mi cuerpo" tiene una relevancia sustancial en la obra de Piñera ya que se podría leer como el primer -y tal vez único- esfuerzo veladamente teórico donde el autor problematiza la dicotomía yo/cuerpo. Con desparpajo, con resignación (y sobre todo con una naturalidad capaz de perturbar a los antiguos espíritus forjados bajo la hegemonía lezemiana), Piñera se anima a teorizar sobre su "maldita circunstancia". Esta teorización es a la vez el registro por escrito de los puntos cardinales de su credo artístico, donde el cuerpo tendrá un papel preponderante. En ese rapto confesional hay sin duda ciertos temores, ciertas motivaciones y una certeza: Virgilio Piñera no ha sido (ni ha querido ser) un artista "distinto" del que ya "es". A pesar de los preceptos imperantes en la literatura cubana oficial de la época, cuyo jerarca mayor (en todo el sentido de la palabra) ha sido José Lezama Lima, hay en las líneas de "Discurso a mi cuerpo" un grito de "independencia artística", es decir: un revolucionario "gesto político". En definitiva, Piñera sienta aquí las bases de su disidencia, de su rechazo a las modas oficiales, y se instala plácidamente en el áspero territorio de la marginalización. Con razón Antón Arrufat (1994) señala:

Como buen marginado, escritor que por sus procedimientos y su visión se ha puesto al margen, en Piñera prevalece -también en Alfred Jarry- el cuerpo sobre el alma o la mente, marginándose así del canon dominante en la cultura occidental, en el que la mente prevalece sobre el cuerpo. Sus relatos intentan una comprobación simple, y a la vez compleja en sus consecuencias: el hombre está hecho de carne, y manifiestan el peligro de la ausencia material, de las partes del cuerpo y de las necesidades corporales, como el hambre, dolor físico, falta de vista o cojera. (p.24) 
Voluntario posicionamiento liberador, la marginalidad de Piñera es una decidida estrategia creativa para situarse en la orilla opuesta de la alta jerarquía de las letras cubanas; no en vano hay un detalle que suele pasar desapercibido: "Discurso a mi cuerpo", como Juan Carlos Quintero Herencia (2002) señala, es un texto “dedicado significativamente a José Lezama Lima” (p.408). ¿Qué se desprende del énfasis de la dedicatoria? ¿Un tributo sarcástico al maestro de una generación? ¿Un rechazo tajante a los orígenes? Sea lo que sea, la mención a Lezama Lima está ahí, y sin embargo nadie, excepto Quintero Herencia, ha reparado en ella. En cambio hay una cantidad ingente de críticos y escritores que no pueden (o no quieren) hablar de Piñera sin omitir el nombre de Lezama. Es posible que esta persistencia conjunta sea de mal gusto. Pero también es posible que sea inevitable: siempre, o casi siempre, se los suele mencionar juntos a la hora de hablar - especialmente- de la obra de Piñera. Desde luego, no pasa lo mismo cuando se habla de Lezama. Es más: si se habla de la obra de Lezama no solo la mención a Piñera sobra sino a cualquier otro escritor cubano o latinoamericano o incluso griego ${ }^{3}$. En resumen: Lezama está solo con Lezama. Y eso es todo. O "casi" todo: porque lo cierto es que la grandiosidad de Lezama escapa a las fronteras impuestas por su propia grandeza, escapa y explota en mil pedazos, y los efectos radioactivos de dicha explosión todo lo contaminan ${ }^{4}$. De esto no está exento ni siquiera Virgilio Piñera (y a lo mejor está bien que así sea). Al fin y al cabo, el Efecto Lezama es muy productivo para abordar la obra de Piñera. En un sentido, es su antítesis: una antítesis que contiene algunos referentes autobiográficos y literarios.

Por el lado autobiográfico, me gustaría mencionar ciertos contrastes clásicos: Lezama era gordo (de una gordura casi enfermiza) y Piñera era flaco (de una flacura casi enfermiza ${ }^{5}$; Lezama se vestía con camisas de cuello y corbata y Piñera, con pantalones baratos y camiseta; Lezama tenía apariencia de ser muy macho (y no

3 Aunque no deja de ser cruel -es decir, no deja de producir cierto placer-separar a Lezama Lima al menos por un momento de esa constelación de dioses, de efigies, de milagros prebarrocos.

4 En otras palabras: el cuerpo que contiene "simbólicamente" la grandeza de Lezama se revienta. Parece otra muestra de mal gusto. O, si se prefiere, una imagen poética afín al universo de Virgilio Piñera.

5 Para resaltar estas diferencias, según Cabrera Infante (1998), Virgilio Piñera escribió una obra de teatro llamada El Flaco y el Gordo, "en la que el Gordo es un glotón atroz que hace referencias a un Maestro, gourmet esencial -las dos caras comilonas de Lezama que se atracaba de comidas que calificaba de exquisitas. El Flaco, como Virgilio, es un hombre hambreado encerrado con el Gordo en un recinto aislado, que termina, premonitoriamente, matando al Gordo, devorándolo - ¿antropofagia intelectual?-y llevando sus ropas, que lo convierten en lo que siempre quiso ser, el Gordo" (p.14). Aquí de nuevo Piñera se vale del cuerpo y de la carne para llevar a cabo una venganza poética no exenta de cierta piedad: tragarse al Maestro es al parecer el primer requisito para "ser" el Maestro. O dicho de un modo un poco más brutal: la antropofagia es legítima en el universo piñeriano siempre y cuando sirva para librarse de la angustia de las influencias de que hablara el gordo Harold Bloom. 
lo era ${ }^{6}$ y Piñera era muy amanerado; Lezama fumaba grandes puros y Piñera, cigarrillos endebles. Además, hay una última imagen aún más definitoria de esta antítesis. Dice Cabrera Infante (1998):

Lezama vivía rodeado de libros, de papeles, de pruebas de galera (siempre estuvo, desde 1937, envuelto en empresas editoriales: revistas, libros, publicaciones) y su asma se alimentaba del polvo que acumula el papel impreso. Virgilio nunca tuvo un libro y hacía gala de esta ausencia que no era carencia. "¿Para qué los voy a almacenar en mi casa?". Me consta que en las dos casas en que le vi vivir no encontré nunca un libro. No creo siquiera que conservara ejemplares de sus propias obras. (p.23)

Aparte de un padre ingeniero, no hay mucho más que una a Lezama y Piñera. En esencia, se trata de dos temperamentos antitéticos aunque no necesariamente antagónicos ${ }^{7}$. De acuerdo con Antonio José Ponte (2002), Piñera encaró el combate con Lezama porque tenía el convencimiento de que estaba en disposición de enfrentar al maestro: "Con cartas y poemas, con diálogos perdidos ya, Virgilio Piñera cebaba aquella antagonía. Si después de publicarse Paradiso ofreció a su contrincante la precedencia, lo hacía para atestiguar que era él y no otro el llamado a secundarlo, el único posible en emparejársele" (p.104). De modo que el arduo antagonismo -en esa época de la historia literaria cubana el "estilo reinante" estaba centralizado, repito, en la figura de Lezama- se podría ver como una "guerra estilística de sucesión". En ese contexto -doradamente barroco e

6 La anécdota de la esquina del Callejón del Chorro, que Cabrera Infante (1998) rememora con venenosa precisión, ilustra mejor este aspecto. En esa esquina Piñera y un amigo se encontraron con Lezama a pleno sol. Lezama acababa de salir de un burdel de varones con cara de satisfacción y tenía un puro recién encendido en la boca. "Lezama notó a los dos artistas (que parecían más bien dos pícaros por su porte pobre y sus sonrisas cínicas), pero no se inmutó y en alta voz, con su acento asmático, dijo: 'Qué, Virgilio, ¿también en busca del unicornio oculto en espesura?'. A lo que contestó Virgilio, extrañamente, pues aunque podía ser ingenioso nunca fue culterano: 'No, Lezama, cubrimos el mismo coto de caza'” (p.21).

7 Antonio José Ponte (2002) dice que este antagonismo no fue tan radical: "Se ha dicho que es fácil detectar lo lezamiano en los poemas iniciales de Virgilio. Puede afirmarse también que un poema como 'La hormiga y la escalera' del último poemario de Lezama Lima, está escrito en lo mejor del aire piñeriano. Y más, algunos poemas de las últimas épocas de ambos resultan bastante canjeables entre sí. Es la historia teatral del flaco que se come al gordo y luego va a ser comido por el flaco" (p.104).

8 La literalidad del soneto "El hechizado" (y la dedicatoria: "A Lezama, en su muerte") corrobora la admiración de Piñera por el maestro de las letras cubanas: "Por un plazo que no pude señalar / me llevas la ventaja de tu muerte: / lo mismo que en la vida, fue tu suerte / llegar primero. Yo, en segundo lugar. / Estaba escrito. ¿Dónde? En esa mar / encrespada y terrible que es la vida. / A ti primero te cerró la herida: / mortal combate del ser y del estar. / Es tu inmortalidad haber matado / a ese que te hacía respirar / para que el otro respire eternamente. / Lo hiciste con el arma Paradiso. / -Golpe maestro, jaque mate al hado-. / Ahora respira en paz. Viva tu hechizo. 9 de agosto de 1976" (Piñera, 2000, p.214). 
intelectual- la obra de Piñera irrumpiría como la contraparte violenta o como un certero dispositivo de ruptura9 .

En el ámbito estrictamente literario, el duelo entre Piñera y Lezama contiene pasajes de intensa fricción. A lo mejor uno de los más elocuentes sea la visión de ambos autores frente al mito de Acteón. El origen del mito, como Julia Cuervo Hewitt (2002) anota, proviene del segundo libro de Las metamorfosis de Ovidio, donde se recrea la historia de Acteón, un cazador joven que se atreve a franquear los límites espaciales impuestos por los dioses. El atrevimiento llega a buen puerto cuando el joven Acteón se interna en el bosque de Diana (Artemisa) y ve a la diosa bañándose con sus ninfas. En señal de castigo, Diana transforma a Acteón en un ciervo. Cuando se ve reflejado en el agua Acteón reconoce su nueva condición, pero no puede reaccionar porque ha perdido la voz. A esas alturas ha perdido el poder de identificación, de manera que es devorado por sus propios perros. "Como todo mito", de acuerdo con Cuervo Hewitt (2002), "la anécdota sufre una serie de transformaciones literarias a través del tiempo en las que se proyectan diferentes etapas del pensamiento estético-filosófico de Occidente" (p.232). Lezama Lima y Piñera no fueron ajenos a esta tentación, aunque el método reinterpretativo dista mucho entre uno y otro.

Lezama, como Cuervo Hewitt (2002) señala, retoma el mito con el propósito de identificar lo americano en Cuba. Desde esta visión americanizada, la figura de Acteón se convierte a su vez en un ciervo en virtud de la contemplación de las musas. En esta instancia Cuervo Hewitt (2002) puntualiza: "El Acteón de Lezama es el poeta, el escritor que, transformado en presa por las musas, es condenado a permanecer en constante vigilia, en un perpetuo acecho, persiguiendo con su escritura las propias imágenes y el mundo que lo acechan y persiguen" (p.232). La aproximación de Lezama al mito, a la "idea" del mito, se da a partir entonces de un respetuoso código intelectual, en cuya ejecución hay una cierta reverencia por la fuente original. En este acto de buena conducta es posible advertir un excesivo aire de fidelidad. Con modales de alumno ejemplar, con pasmosa obedien-

9 Esta coyuntura por la "supremacía estilística" tal vez podría enmarcarse dentro de lo que Deleuze y Guattari (1978) denominaran como "una literatura menor”. ¿Cuáles son las principales características de esta denominación? Primero: Una literatura menor es la literatura que una minoría realiza dentro de una lengua mayor. Segundo: Toda literatura menor es política. Tercero: En la práctica de una literatura menor todo adquiere un valor colectivo. Deleuze y Guattari condensan esta denominación con las siguientes palabras: "Las tres características de la literatura menor son la desterritorialización de la lengua, la articulación de lo individual en lo inmediato-político, el dispositivo colectivo de enunciación. Lo que equivale a decir que 'menor' no califica ya a ciertas literaturas, sino las condiciones revolucionarias de cualquier literatura en el seno de la llamada mayor o establecida" (p.31). 
cia, Lezama decide retomar el mito porque retomándolo se vincula de paso con una tradición, una tradición literaria poderosa, clásica e inmortal: la reescritura del mito es la forma más efectiva de Lezama a la hora de reclamar su lugar en el Partenón de los grandes de la historia.

En cambio Piñera (1999) se aproxima al mito desde otra perspectiva: "El señor del sombrero amarillo se me acercó para decirme: '¿Querría usted, acaso, formar parte de la cadena? -y sin transición alguna añadió- Sabe, de la cadena Acteón'. ¿Es posible...? -le respondí-. ¿Existe, pues, una cadena Acteón?”” (p.41). En las líneas iniciales ya se siente la "temperatura" del cuento ${ }^{10}$. El narrador está incrédulo ante la posibilidad de pertenecer a una cadena que no sabe si existe. Unas líneas después la situación se va aclarando, y la temperatura empieza a subir (o a bajar, todo depende): "Sin poderme contener, abrí los dos primeros botones de su camisa y observé atentamente su pecho" (p.41). A partir de este momento hay un erótico contrapunto coral de manos, uñas, voces y cuerpos: “'Sí -dijo él-, las dos razones del caso Acteón. La primera (a su vez extendió su mano derecha y entreabrió mi camisa), la primera es que el mito de Acteón puede darse en cualquier parte'. Yo hundí ligeramente mis uñas del pulgar y del meñique en su carne" (p.41). Y luego el promotor de la cadena hunde también las uñas del pulgar y del meñique en el pecho del narrador. Al mismo tiempo los botones de las camisas se siguen abriendo. Hay algunos quejidos; no son muy fuertes pero son audibles ${ }^{11}$. Y más tarde hablan de víctimas, de perros, de Acteón:

"Tanto podrían los perros ser las víctimas como los victimarios; y en este caso, ya sabe usted lo que también podría ser Acteón." Entusiasmado por aquella estupenda revelación no pude contenerme y abrí los restantes botones de su camisa y llevé mi otra mano a su pecho. "¡Oh -grité yo ahora-, de qué peso me libra usted! ¡Qué peso quita usted de este pecho!". Miraba hacia mi pecho, donde, a su vez, él había introducido su mano libre y,

10 En cuanto la temperatura de sus cuentos, Piñera resaltó un par de aspectos en el prólogo de la primera edición de Cuentos fríos; sobre esos aspectos volveré más adelante.

11 En esta misma línea de erotismo estaría la famosa secuencia de La carne de René: (...) así también Roger sacó su lengua y tomando un dedo del pie de René, la aplicó una y otra vez a fin de cerciorarse de la bondad de su punta... Roger se asemejaba a esos calígrafos que pasan su pluma por los bordes del papel. Soltó el dedo y se trasladó a la cara. Pasó su mano por debajo de la cabeza de René y apoyó la otra en su pecho. Entonces, miró a Cochón. Este fue señalando las lenguas que debían secundar la de Roger. Una por cada parte del cuerpo: dos piernas, dos brazos... -Roger, abra usted la sesión - dijo. Roger lamió profundamente la frente de René. Movió la cabeza con aire de duda. Pasó la lengua por los labios del rebelde. Volvió a mover la cabeza. -¿Qué pasa, Roger? -preguntó. -Pétrea -se limitó a decir Roger" (Piñera, 1985, p.113). 
acompañando la palabra a la acción, me decía: "Claro, si es tan fácil, si después de comprenderlo es tan sencillo...." Se escuchaba el ruido característico de las manos cuando escarban la tierra. (p.42)

Del final de la historia se desprenden al menos tres consideraciones: 1) Piñera se aproxima al mito hurgando parsimonioso en la carne, sin precipitarse, sin perder la compostura, sin atragantarse, dejándose llevar plácido por la ceremonia del desgarramiento (un proceso que a su vez tiene la virtud de reducir los dos cuerpos a uno solo). 2) En la "reescritura" del mito no hay ninguna filiación con sus antecesores sino más bien un rechazo cómico, cósmico, canónico. Es natural: Piñera se resistió a ser parte de cualquier tradición (cubana o universal, es lo de menos) y sin duda por eso siempre fue un poco alérgico a "figurar"; toda su vida se mantuvo (por convicción o por capricho de los dictadores de turno) a la sombra de los reflectores de la gloria. 3) Piñera aborda el mito desde la irreverencia, desde el distanciamiento paródico -y en esto se distancia aún más de Lezama Lima.

\section{Guerra fría: el cuerpo despedazado}

A pesar de que "El caso Acteón" es uno de los puntos literariamente más divergentes entre los dos antagonistas, lo cierto es que las secuelas de este conflicto público y privado se esparcieron -con indisimulada fascinación- hacia otros textos literarios, entre los que valdría la pena mencionar también el cuento "El conflicto", incluido en Cuentos fríos y fechado en 1956.

Irónica vendetta piñeriana en contra del grupo de Orígenes, revista dirigida por José Lezama Lima, "El conflicto" recapitula el drama final de Teodoro, un prisionero condenado a morir fusilado. Con aparentes influencias del existencialismo de Jean Paul Sartre -en concreto, del cuento "Le mur"-, Piñera lanza de nuevo un par de dardos hacia su principal contrincante literario. Esta cuestión ha sido analizada en profundidad por Aída Beaupied (2002), cuyo riguroso estudio saca a la luz varios datos productivos acerca del antagonismo Lezama-Piñera. Inicialmente, hay en el cuento secretas alusiones; no en vano Beaupied (2002) ha contabilizado ocho menciones al Narciso (es necesario aclarar en este punto que el primer poema publicado por Lezama fue "Muerte de Narciso"): cuatro en la segunda parte -"Transmutación"- y cuatro en la última -"Fusilamiento"-. Además, "hay un paralelo implícito entre el proyecto inicial de Teodoro y las ideas que sustentan la poética de Lezama" (Beaupied, 2002, p.279). Desde luego, el 
proyecto no es del todo claro o al menos no es claro para el oficial que interroga a Teodoro. Es posible que el problema de comprensión obedezca al lenguaje, y este sería el mismo problema que tendría que sortear cualquier lector de Lezama. La incomprensión del proyecto es aún más diciente "cuando Teodoro le explica al oficial que su estrategia para burlar lo ineluctable equivale a capturar la Imagen que sirve de puente al plano trascendental" (Beaupied, 2002, p.280). En una primera instancia el oficial "no entiende". Pero después "sí" entiende y reacciona como reaccionará el autor del cuento. "La reacción del oficial", de acuerdo con Beaupied, "nos confronta con la lectura que hace Piñera del proyecto lezamiano: la sublimación del deseo a través de la imagen poética es una negación de la vida" (p.280).

En la forma en que Piñera plantea el rechazo hay un elemento llamativo, ya que el rechazo lo efectúa no por falta de comprensión sino más bien porque "ya" ha comprendido. De la comprensión (o, si se quiere, de la "buena" lectura que hace de Lezama), surge entonces el rechazo automático de Piñera hacia semejante postura estética. En concreto, el cuento vendría a ser el campo de batalla de dos categorías complejas: el estilo y las ideas. Por supuesto, en ambos casos se trata de categorías antagónicas en los dos escritores. De la primera (el estilo) hay una muestra representativa en el penúltimo párrafo del cuento:

Respondiendo en gracioso homenaje a este principio humano vocal, flotaba magnífica en la neblinosa atmósfera del alba, tentadora y aguda como la gama sonora de una chirimía árabe, la diamantina sonrisa de Teodoro; era de tal languidez imperativa que el oficial, sollozando sin lágrimas, abatió sobre la tierra, vuelto una fosforescente centella velocísima, el brazo que aprisionaba el sable de oro. (Piñera, 1999, p.135)

Sin ánimo de incurrir en un ejercicio de literatura comparada, valdría la pena detenerse en los verbos, en los sustantivos, en los adjetivos lezamianos de este cuento fundacional de Piñera: "neblinosa atmósfera del alba", "tentadora y aguda como la gama sonora de una chirimía árabe", "diamantina sonrisa", "languidez imperativa", "vuelto una fosforescente centella velocísima". En comparación con otros relatos de Cuentos fríos es evidente que hay aquí muchas palabras que "rechinan", que resultan tal vez demasiado postizas, artificiales, preciosistas. Desde luego, no tengo nada en contra de las florituras del lenguaje, pero sí me parece que el lenguaje de este cuento (o mejor, la ostentación lingüística) difiere de la compleja sencillez del estilo general de Piñera. Con respecto a los comienzos 
literarios de Piñera, Antón Arrufat (1999) sostiene: "Sus cuentos requerían otros procedimientos, y él, gradualmente, desde la publicación de su primer relato, 'El conflicto', en 1942, se propuso con energía forjarse esos procedimientos, su manera de narrar, la menos barroca que existe, en oposición franca y declarada al barroquismo de Lezama, su gran antagonista" (p.30).

En el plato estilístico, pues, el "primer cuento" de Piñera es tan barroco que parece escrito por Lezama. De ahí que me anime a asegurar que en esa época aún no se había librado del "embrujo lezamiano" (y si se hubiera librado el cuento no habría sido más que una feroz parodia en contra de la hegemonía barroca en las letras cubanas de aquella época). Por el momento (y hasta que se demuestre lo contrario) sigo creyendo que esta lectura es la correcta. En cuanto a las ideas, las palabras de Beaupied (2002) condensan mejor el parte de guerra:

Queda claro también que ese enfrentamiento concluye con la derrota del proyecto literario de Lezama, el cual es condenado a muerte y fusilado en el gesto final del brazo que baja para realizar la ejecución de Teodoro. Es significativo que en "El conflicto" los dos personajes terminen coincidiendo en proponer una única solución a la problemática existencial. Esa confluencia me dice que lo que aparentaba ser dos visiones opuestas se resuelven dialécticamente en una; como si los dos Narcisos -el de la imagen en el espejo y el que la contempla- terminarán resolviendo su aparente diferencia. La resolución me dice también que el autor de este cuento escribe para asegurar la posición ideológica que lo distingue de su "primogénito" precursor. (p.285)

Que el "símbolo irónico" de la historia sea el Narciso no deja de ser llamativo. Después de todo, no hay otra figura mítica que capture de un modo más certero la esencia de la belleza. A partir de la contemplación, de la excesiva contemplación, cualquier rostro (en especial los rostros de quienes apostaron "todo" a la belleza, a la imagen, a la exteriorización, es decir: los rostros del homosexual) entran en un irremediable ciclo de deterioro. La contemplación acrecienta el paso del tiempo, o si se quiere, la destrucción. En esto Piñera vuelve a ser profundamente coherente ya que se vale del rostro para insistir una vez más en la importancia del cuerpo. En "El conflicto", el oficial le advierte a Teodoro: "No comprendo cómo podría salvarse usted -objetó el oficial- si insiste en dar cuerda al suceso fusilamiento: ¿no determinaría esto la pérdida de su cuerpo" (Piñera, 1999, p.132). El cuerpo es el fundamento de su apuesta creadora. En "El conflicto" parte del ros- 
tro, del rostro de un condenado a muerte, pero en otros cuentos Piñera incursiona, asedia al cuerpo desde otras perspectivas menos glamorosas. Lúcido e insistente, vuelve siempre sobre el cuerpo con el fin de dilucidar la trama secreta de una vieja obsesión. En cierto sentido el cuerpo se convertirá al final en su gran poética. Para Antón Arrufat (1999) esta cuestión se resuelve en los siguientes términos:

\begin{abstract}
En Piñera no vamos del alma al cuerpo, vamos del cuerpo al alma, a un alma hipotética. Aunque en el mundo de Piñera no existe Dios, combate en su escritura contra nuestras supervivencias teológicas, y casi nos propone, en una inversión herética, que el cuerpo es el creador del alma. Por eso su obra es una herejía que nos enfrenta con una única realidad posible, perecedera, enfermiza, efímera: la realidad de nuestro cuerpo. El camino de toda carne en Virgilio Piñera es la carne misma. Su experiencia, su exploración y su aceptación final. Lo que en cierta medida él no pudo alcanzar en la relación con su cuerpo. (p.27)
\end{abstract}

Si se toma la primera parte de la cita de Arrufat, si se sigue transitando por esa misma "senda teológica" hasta el último recoveco, emerge entonces una extraña reafirmación: el cuerpo es el alma de Piñera. De esta devoción corporal hay sin duda muchas señales tanto en su obra en general (tal como lo he expuesto sintéticamente en los párrafos precedentes de este trabajo) como en Cuentos fríos en particular. En efecto, a través del cuerpo, de la apropiación del cuerpo como "fetiche literario" -en ese persistente trabajo de autovoyeurismo el análisis, la digresión, el diálogo, la descripción o el monólogo serán estrategias fructíferas-, Piñera intenta lidiar con su convulsa intimidad. Ante el cuerpo, solo ante el cuerpo, con la dicha de los grandes penitentes, con una mueca de sarcasmo mayor, los sospechosos pecados de la carne piñeriana son expiados gracias al sospechoso milagro de la confesión. Ya no hay (aunque tal vez nunca hubo) culpa. A esas alturas solo hay una revelación (a esto alude la segunda parte de la cita anterior de Arrufat): el cuerpo es lo "único" vulnerable, y en ese permanente estado de vulnerabilidad se consolida en su materialidad siempre amenazada, siempre en constante estado de alerta, siempre al borde de la descomposición, de la descomposición ajena por completo a las bellos efectos de la cosmética. Nunca hay rastros de glamour en esos drásticos cambios de look aunque tampoco hay ningún padecimiento ni dolor. Cuando los protagonistas de "La caída" se ven frente a frente asumen sin protestar el curso del destino: "No nos dijimos palabra, pero sabíamos que el despeñamiento sería inevitable. En efecto, pasado 
un tiempo indefinible, comenzamos a rodar" (Piñera, 1999, p.35). Los cuerpos iniciales desaparecerán, se irán poco a poco desmembrando y al final las partes más preciadas ni siquiera sufrirán:

Como mi única preocupación era no perder los ojos, puse todo mi empeño en preservarlos de los terribles efectos de la caída. En cuanto a mi compañero, su única angustia era que su hermosa barba, de un gris admirable de vitral gótico, no llegase a la llanura ni siquiera ligeramente empolvada. Entonces yo puse todo mi empeño en cubrir con mis manos aquella parte de su cara cubierta por su barba; y él, a su vez, aplicó las suyas a mis ojos. (Piñera, 1999, p.36)

En "La caída" los ojos y la barba de los protagonistas no sufrirán en el descenso, tal vez porque los ojos serán los únicos testigos del desmembramiento. En lugar de cerrarlos, en lugar de bloquear el horror, el personaje "asume" complacido el reto de verse convertido en "otro". Al llegar al césped de la llanura ya no hay cuerpo, ya solo hay un par de ojos. Atentos y acuciosos, los ojos sobreviven al cuerpo, contemplan extasiados la barba resplandeciente y son a la vez la prueba de una existencia corporal previa. Este mismo efecto degenerativo, esta especie de efecto dominó, se presenta también en "La carne". Allí el cuerpo es desde el principio un elemento utilitario. La escasez de carne en el pueblo se ha convertido de golpe en una prohibición general cuyo alcance judicial al parecer no podría condenar a Anseldo. Por eso hace lo siguiente: "Con gran tranquilidad se puso a afilar un enorme cuchillo de cocina, y, acto seguido, bajándose los pantalones hasta las rodillas, cortó de su nalga izquierda un hermoso filete" (Piñera, 1999, p.38).

¿Es punible el acto de cortar un "hermoso filete ${ }^{12}$ " de la propia nalga de su propio cuerpo? ¿No es el cuerpo un templo sacro, privado, profanable? Y por eso mismo ¿no puede ser acaso motivo de violencia (o allanamiento) por parte de su propietario? Como bien apunta Dara E. Goldman (2003): "El doble significado de la palabra carne enfatiza además la ironía: los habitantes del pueblo literalmente destruyen su propia carne para no sufrir las consecuencias de verse privados de la carne" (p.1008). De cualquier modo la conducta desafiante de Anseldo -ante

12 A propósito: "hermoso" o "hermosa" son adjetivos recurrentes en Piñera. En este mismo cuento, sin ir tan lejos, se lee: "hermoso espectáculo", "hermosa boca", y también "bellos dedos de los pies", entre otros. 
la propuesta vegetariana conviene perder hasta la lengua- se propaga como una epidemia por el pueblo. Anseldo, el responsable de la primera mutilación (una primera mutilación que a su vez desencadena una irrefrenable mutilación colectiva ${ }^{13}$ ), se encargará más adelante de dar ejemplo en la plaza principal:

Una vez allí hizo saber que cada persona cortaría de su nalga izquierda dos filetes, en todo iguales a una muestra en yeso encarnado que colgaba de un reluciente alambre. Y declaraba que dos filetes y no uno pues si él había cortado de su propia nalga izquierda un hermoso filete, justo era que la cosa marchase a compás, esto es, que nadie engullera un filete menos. Una vez fijados estos puntos, diose cada uno a rebanar dos filetes de su respectiva nalga izquierda. Era un glorioso espectáculo, pero se ruega no enviar descripciones. (pp.38-39)

La carne se transforma entonces en un artículo de primera necesidad, un artículo que verdaderamente da placer a quienes lo disfrutan, a quienes se atreven a disfrutarlo. En Piñera cualquier mutilación, cualquier "parte" que se pierda, no tiene (no puede tener) una connotación negativa. Es más bien lo contrario, como si cualquier pérdida se resumiera en la siguiente consigna gastronómica: todo lo que comes, sobre todo si es tuyo, te hace feliz. O te hace ser tú.

Desde otra aproximación crítica, "La carne" sería también definitorio en la configuración de la poética piñeriana. De hecho, la primera frase del cuento podría ser el epígrafe de Cuentos fríos (e inclusive de la totalidad de su obra): "Sucedió con gran sencillez, sin afectación” (Piñera, 1999, p.38). ¿Hay una "gran sencillez" porque no hay "afectación”? ¿O acaso no hay "afectación” en virtud de una "gran sencillez"? Sea cual sea el orden del proceso, lo cierto es que esta armoniosa conjunción ("gran sencillez" + "sin afectación") no solo determina el "hecho" sino -sobre todo- las condiciones a partir de las cuales el "hecho" puede ser narrado. Por supuesto, el "hecho" es el conflicto yo-cuerpo/cuerpo-yo, cuya exposición narrativa está fundamentada en una "gran sencillez sin afectación". Así, pues, el conflicto yo-cuerpo/cuerpo-yo puede ser expuesto. O mejor dicho: así el "hecho narrativo" (conflicto yo-cuerpo/cuerpo-yo) puede "suceder" con discreción, sin énfasis, como si esa "gran sencillez sin afectación" estuviera siempre al margen

13 En los cuentos de Piñera, una vez se inicia el desmembramiento del cuerpo, una vez se inicia esa especie de "derrumbe corporal", ya nada se podrá restaurar. De alguna manera este efecto garantiza la extinción del cuerpo. 
de la descomposición inevitable de la carne. En síntesis: narrar la descomposición pero sin descomponerse, sin dejarse desgarrar, sin dejarse afectar, siendo inmune al material que se descompone incluso mientras se narra, como si ese cuerpo a punto de descomponerse fuera en realidad otro cuerpo, otro cuerpo que el yo no puede ya desechar, traicionar, malinterpretar porque en esa instancia final el yo valora el cuerpo con la misma intensidad que el cuerpo valora al yo. Valorar la descomposición: tal sería la consigna literaria de Virgilio Piñera, cuya equivalencia significativa estaría determinada, según se desprende de las palabras que el propio Piñera (1956) escribiera en el prólogo de la primera edición de Cuentos fríos, por la frialdad:

Como la época es de temperaturas muy altas, creo que no vendrán mal estos Cuentos fríos. El lector verá, tan pronto se enfrente con ellos, que la frialdad es aparente, que el calor es mucho, que el autor está bien metido en el horno y que, como sus semejantes, su cuerpo y su alma arden lindamente en el infierno que él mismo se ha creado.

Son fríos estos cuentos porque se limitan a exponer los puros hechos. El autor estima que la vida no premia ni castiga, no condena ni salva, o, para ser más exactos no alcanza a discernir esas complicadas categorías. Sólo puede decir que vive; que no se le exija que califique sus actos, que les dé un valor cualquiera o que espere una justificación al final de sus días. En realidad, dejamos correr la pluma entusiasmados. De pronto las palabras, las letras se entremezclan, se confunden; acabamos por no entender nada, recaemos en la infancia, parecemos niños con caramelos en las bocas. $Y$ entonces, espontáneo, ruidoso, brota ese misterioso balbuceo: ba, ba, ba, ba... (p.1)

El frío piñeriano alude entonces a las virtudes innatas que el narrador ha desarrollado, ya que narra los hechos sin dejarse "contaminar" por el contenido, por las imágenes muchas veces fulminantes de la descomposición del conflicto yocuerpo/cuerpo-yo. En el fondo, dicha "frialdad" se encamina a la configuración de un anestésico dispositivo narrativo. Indiferente e impertérrito, el narrador se mantiene suspendido en otra dimensión: nada puede afectarlo, nada puede sacarlo de ese trance en el cual los hechos emergen. Con pulso, con los ojos muy abiertos, se rinde anestesiado ante el poderío de su propia narración. Adicionalmente, la frialdad piñeriana alude a su vez a un opaco pliegue autobiográfico. En una entrevista con Yonny Ibáñez (2002), Virgilio Piñera confiesa: 


\begin{abstract}
Yo, en el momento de la creación, también sufro una desazón, pero como dije ya hace tiempo en una entrevista que ustedes conocen, el mundo de la literatura es un infierno frío. Es el único infierno frío que existe. Por eso le puse a la selección de mis cuentos Cuentos fríos. Yo soy así, como un hielo; aparentemente no sucede nada, pero tras ese cristal, esa superficie, está el infierno del creador. (p.481)
\end{abstract}

Noble denominación del martirio artístico, el infierno frío del narrador piñeriano arde intermitente en cada cuento arrasando a su paso a los personajes, guiándolos en silencio, sin inmutarse, sin el menor apremio, hacia la desintegración definitiva. En el infierno frío de Virgilio Piñera hay leyes. Y, desde luego, condenas. Contra eso se enfrenta una y otra vez la corporalidad de los personajes incluso más allá de la muerte. En "El insomnio", un cuento de no más de quince líneas, la corporalidad sigue causando problemas:

El hombre se acuesta temprano. No puede conciliar el sueño. Da vueltas, como es lógico, en la cama. Se enreda entre las sábanas. Enciende un cigarrillo. Lee un poco. Vuelve a apagar la luz. Pero no puede dormir. A las tres de la madrugada se levanta. Despierta al amigo de al lado y le confía que no puede dormir. Le pide consejo. El amigo le aconseja que haga un pequeño paseo a fin de cansarse un poco. Que enseguida tome una taza de tila y que apague la luz. Hace todo esto pero no logra dormir. Se vuelve a levantar. Esta vez acude al médico. Como siempre sucede, el médico habla mucho pero el hombre no se duerme. A las seis de la mañana carga un revólver y se levanta la tapa de los sesos. El hombre está muerto pero no ha podido quedarse dormido. El insomnio es una cosa muy persistente. (Piñera, 1999, p.90)

A pesar de que el conflicto yo-cuerpo/cuerpo-yo se impone incluso después de la muerte, Virgilio Piñera asume en Cuentos fríos esa confrontación -en el fondo se trata de una confrontación consigo mismo, o sea, una verdadera confrontación artística- hasta sus últimas consecuencias. En este sentido, la confrontación piñeriana adopta en realidad el sentido de una transformación. Pero "transformación" no quiere decir "evolución" porque la "transformación", en los términos inscritos en la poética de Piñera, cancela plenamente cualquier tipo de progresión, cualquier "avance positivo". Es decir, se trata más bien de una "transformación negativa" porque sigue siendo productiva incluso con la muerte, con la articula- 
ción atemporal del conflicto yo-cuerpo/cuerpo-yo. Con razón Dara E. Goldman (2003) concluye: "Varias de estas historias presentan un encuentro disruptivo entre las entidades opuestas. Aunque este encuentro demuestra ser destructivo no es inequívocamente negativo, ya que el conflicto no es necesariamente un obstáculo a superar o eliminar. Más que trascender la destrucción, la narrativa culmina en un binario irreductible" (p.1007). Así, pues, hay en esos "cuentos fríos" ecos permanentes de esta confrontación/transformación, climatizada a la medida de las obsesiones de Piñera, donde nunca hay sangre pero sí hay restos brillantes del cuerpo desintegrado, como si fuera una evidencia adicional, una evidencia concluyente de la confrontación/transformación que sucede (y, sobre todo, "se" sucede con una "gran sencillez sin afectación") en aquel "infierno frío" en el que los personajes se han desintegrado, al fin, para poder ser lo que siempre han sido.

\section{Referencias bibliográficas}

Alberto, E. (2002). "De Informe contra mí mismo". R. Molinero (Ed.), La memoria del cuerpo. Puerto Rico: Editorial Plaza Mayor.

Arrufat, A. (1994). Virgilio Piñera: entre él y yo. La Habana: Ediciones UNIÓN. Arrufat, A. (1999). "Un poco de Piñera". Prólogo de los Cuentos completos de Virgilio Piñera. Madrid: Alfaguara.

Beaupied, A. (2002). "Conflictos y transmutaciones en la poética antilezamista de Virgilio Piñera”. R. Molinero (Ed.), La memoria del cuerpo. Puerto Rico: Editorial Plaza Mayor.

Cabrera Infante, G. (1998). Vidas para leerlas. Madrid: Alfaguara.

Cuervo Hewitt, J. (2002). “'El caso Acteón': el caso Piñera”. R. Molinero (Ed.), La memoria del cuerpo. Puerto Rico: Editorial Plaza Mayor.

Deleuze, G. \& Guattari, F. (1978). Kafka. Por una literatura menor. (Trad.) Jorge Aguilar Mora. México: Era.

Foucault, M. (2008). Nietzsche, la genealogía, la historia. (Trad.) José Vázquez Pérez. Valencia: Pre-textos.

Goldman, D. E. (2003). "Los límites de la carne: Los cuerpos asediados de Virgilio Piñera”. Revista Iberoamericana, LXIX(205). Web. Último acceso: 17 de agosto de 2016.

Ibáñez, Y. (2002). "Entrevista de Yonny Ibáñez con Virgilio Piñera en ocasión de su cumpleaños". R. Molinero (Ed.), La memoria del cuerpo. Puerto Rico: Editorial Plaza Mayor.

Piñera, V. (1956). "Nota introductoria". Cuentos fríos. Buenos Aires: Losada. 
Piñera, V. (1985). La carne de René. Madrid: Alfaguara.

Piñera, V. (1990). "Discurso a mi cuerpo". Unión, 10(III), 35-36.

Piñera, V. (1999). Cuentos completos. Madrid: Alfaguara.

Piñera, V. (2000). La isla en peso. Obra poética. Compilación y prólogo de Antón Arrufat. Barcelona: Tusquets.

Ponte, A. J. (2002). "La lengua de Virgilio". R. Molinero (Ed.), La memoria del cuerpo. Puerto Rico: Editorial Plaza Mayor.

Quintero-Herencia, J. (2002). "Virgilio Piñera: los modos de la carne”. R. Molinero (Ed.), La memoria del cuerpo. Puerto Rico: Editorial Plaza Mayor.

Quiroga, J. (1995). "Fleshing out Virgilio Piñera from the Cuban Closet". E. L. Bergmann \& P. J. Smith (Eds.), ¿Entiendes? Queer Readings, Hispanic Writings. Durham: Duke University Press.

Quiroga, J. (1999). “Outing Silence as Code”. Tropics of Desire: Interventions from Queer Latino America. New York, NY: New York University Press.

Cómo citar este artículo: Charry, L. (2016). Los rituales de la descomposición del cuerpo en Cuentos fríos de Virgilio Piñera. Cuadernos de Literatura, (23), 181-199. DOI: http://dx.doi.org/cl.23.2016.9 